This item was submitted to Loughborough's Research Repository by the author.

Items in Figshare are protected by copyright, with all rights reserved, unless otherwise indicated.

\title{
Using mechatronics technology to assess pressure filtration
}

PLEASE CITE THE PUBLISHED VERSION

PUBLISHER

(C) Elsevier

VERSION

AM (Accepted Manuscript)

LICENCE

CC BY-NC-ND 4.0

REPOSITORY RECORD

Tarleton, E.S.. 2009. “Using Mechatronics Technology to Assess Pressure Filtration”. figshare. https://hdl.handle.net/2134/4824. 
This item was submitted to Loughborough's Institutional Repository (https://dspace.lboro.ac.uk/) by the author and is made available under the following Creative Commons Licence conditions.

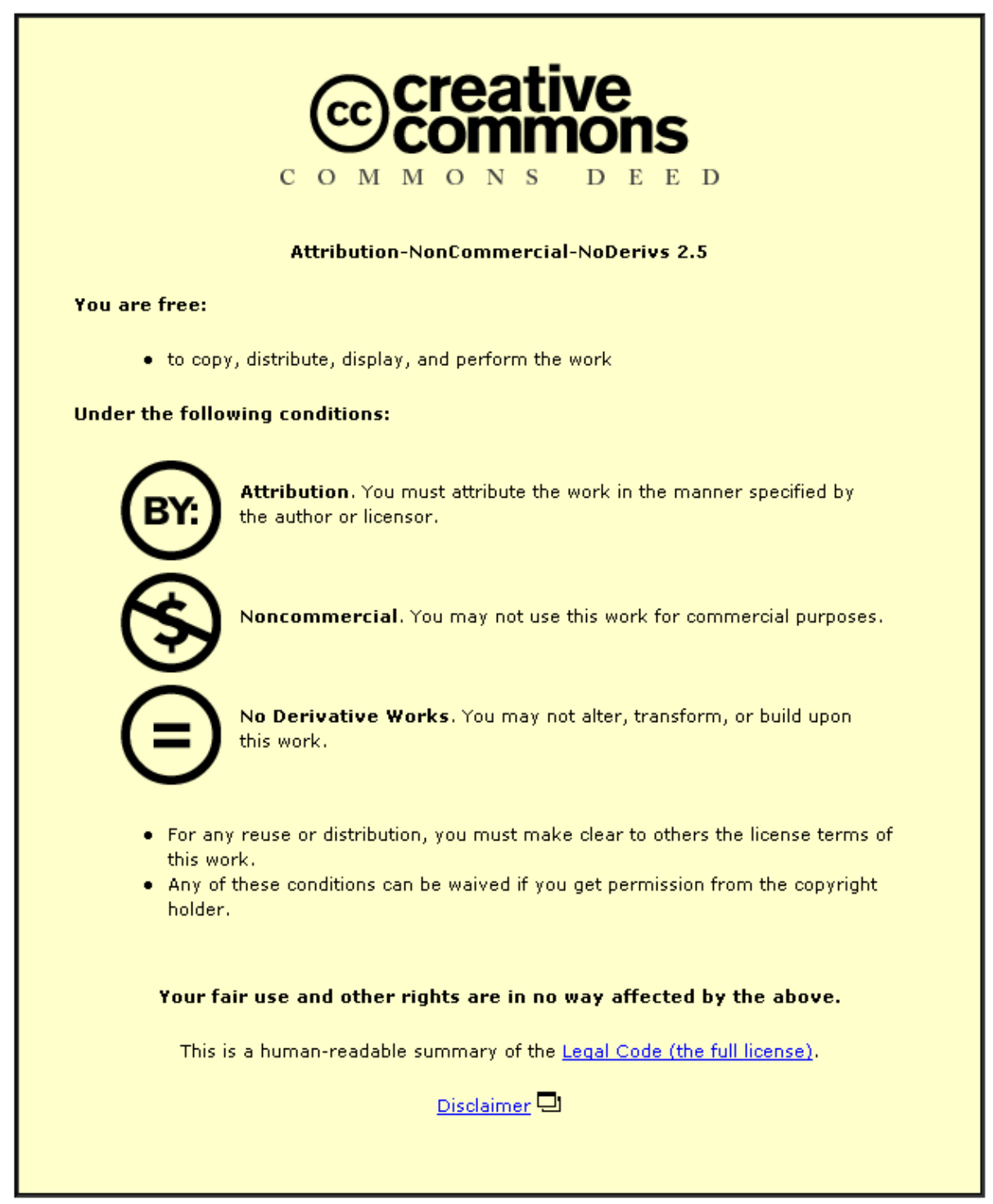

For the full text of this licence, please go to: http://creativecommons.org/licenses/by-nc-nd/2.5/ 


\title{
USING MECHATRONICS TECHNOLOGY TO ASSESS PRESSURE FILTRATION
}

\author{
E.S. Tarleton (e.s.tarleton@lboro.ac.uk) \\ Department of Chemical Engineering, Loughborough University, Loughborough, Leics., LE11 3TU, \\ UK.
}

\begin{abstract}
This paper describes some recent (initial) developments in laboratory scale cake filtration technology which may ultimately lead to the production of standard equipment for assessing filtration performance. The principles of mechatronics, which integrates electronics, computers, process control and mechanical systems, have been used to provide a state-of-the-art pressure filtration apparatus capable of performing repeatable experiments over a range of pressure/flow regimes commonly encountered in industrial filtrations. Data obtained at constant pressure and proportionally controlled variable pressure are presented to illustrate the scope of the apparatus and the benefits of removing operator interference and damaging pumping operations from filtration experiments. It is shown how scale-up parameters (obtained for aqueous mineral suspensions) can be used to successfully predict constant pressure filtration performance and the problems which can arise when predictions of more compressible variable pressure filtrations are made using data obtained at constant pressure.
\end{abstract}

\section{KEYWORDS}

Cake filtration; Compressibility; Mechatronics; Process control; Filter design

\section{INTRODUCTION}

Of principal interest in this paper is cake filtration, a widely used unit operation which relies on the preferential entrapment of particulates on a semi-permeable medium under the action of an imposed pressure gradient. The filter medium which is positioned normal to the bulk flow of suspension is relatively thin and provides the separating surface only during the initial stages of filtration, after which it acts primarily as support to the growing filter cake. The flow of liquid through the cake induces viscous drag forces on the constituent particles. If the cake structure is able to withstand the cumulative effect of these forces throughout a filtration to give a uniform and time-independent cake porosity, then the cake is regarded as incompressible. Otherwise, particle rearrangement occurs to induce a porosity gradient through the cake height. Such a cake is considered to be compressible with the maximum solids concentration occurring at the cake/filter medium interface.

By their nature filtrations are transient processes, usually involving compressibility and thus time dependent changes in cake properties. Whilst previous experimental work has undoubtedly progressed our understanding of incompressible and compressible cake filtration, it should be realised that the majority (through necessity) utilised relatively elementary equipment. Basic filtration data can be derived in laboratories from a single leaf filter operating at either constant under- or over- pressure. Relatively small volume samples of slurry are filtered and data are usually manually recorded. Samples from tests are analysed, and typical filtration and cake formation rates as well as values for specific cake resistance and cake porosity are calculated. When a skilled operator performs experiments the method can give sufficiently reliable results for filter design work [1]. In some cases it is possible to obtain data for sequential operations such as those performed during a filter cycle, though performing these experiments manually gives limited information and can introduce significant errors unless care is taken. It is probably fair to say that a significant proportion of previous filtration research and data acquisition by commercial 
organisations has been blighted by experimental difficulties, the skill (or otherwise) with which experiments are performed, the lack of standard test methods and to some extent a lack of consistent analysis procedures. The need to manually perform tests and adjust operational parameters to maintain chosen experimental conditions are variables which have led to the widespread use of heuristics or 'rules-of-thumb' by filter manufacturers.

It is also interesting to note that the vast majority of experimental and theoretical filtration research has been concerned with the use of a constant pressure gradient [e.g. 2-11]. Whilst this mode of filtration is relatively easy to perform in the laboratory it is not always employed in industrial scale filtrations. Here, it is perhaps more normal to transport suspensions into filter chambers using either positive displacement or centrifugal pumps and perform filtrations according to the pressure and flow characteristics of the pumping device. A few researchers have suggested that data obtained at constant pressure may not correctly predict filtrations over other pressure regimes and some have attempted difficult laboratory experiments in order to assess performance at constant flow/variable pressure or variable pressure/variable flow [12-17]. Due to experimental constraints only limited progress has previously been possible and it is difficult to resolve the inherent problems of more conventional apparatus/methods, such as particle breakage and surface modification by pumps, with confidence.

With the advent of the microprocessor, the ability to perform reliable tests over ranges of operating conditions now exists as does the potential to move away from heuristics towards standard filtration apparatus and analysis procedures. The work presented in this paper considers the issues raised and illustrates a novel approach to experimental pressure filtration where potentially variable operator interference has been eliminated and replaced by a mechatronics philosophy which integrates electronics, computer technology, control philosophies with a cake filtration system.

\section{EXPERIMENTAL PROCEDURES}

The schematic in Figure 1 shows the principal components of a state-of-the-art, laboratory scale pressure filtration apparatus capable of automated data acquisition over the range of pressure/flow regimes of commercial interest. The level of hardware and software sophistication can be varied according to requirements.

The basic hardware comprised of a stainless steel (s/s) dead-end Nutsche filter (area 5 to 500 $\mathrm{cm}^{2}$ ) and a s/s suspension storage vessel connected by s/s piping and computer controlled electropneumatic valving. The storage vessel incorporated a temperature sensor and stirrer and (if desired) the filter cell could be rotated to allow filtration onto upward, downward or sideways facing filter surfaces. A heater/cooler system regulated the temperature of the filter cell and storage vessel by continuously passing a fluid through their surrounding jackets to facilitate operation over the range -5 to $70^{\circ} \mathrm{C}$. All data reported in this paper were obtained at a temperature of $25^{\circ} \mathrm{C}$ with a downward facing filter having an area of $80 \mathrm{~cm}^{2}$ (except one data sequence obtained with a filter of area $23 \mathrm{~cm}^{2}$ ). Various transducers attached to the apparatus allowed pressures and other measured parameters to be recorded and/or controlled by the interfaced computer and dedicated software.

The pressures required to progress filtrations were provided by compressed air and an electronic pressure regulator over the range 10 to $600 \mathrm{kPa}$. The regulator was adjusted by signals from the computer and the filtrate flow rate was semi-continuously transmitted to the computer via successive timed readings of mass from an electronic balance; the balance being capable of delivering up to 10 readings $\mathrm{s}^{-1}$ whilst transient changes were occurring through the addition of filtrate. Constant pressure filtrations could be performed by providing an essentially constant signal to the regulator. By monitoring the flow rate, use of a negative feedback control algorithm of the general form: 
$p=p_{s}+K\left(\varepsilon+\frac{1}{T_{i}} \int_{0}^{t} \varepsilon d t+T_{d} \frac{d \varepsilon}{d t}\right)$

allowed variable pressure filtrations to be performed without changing suspension properties through inappropriate pumping operations. In eqn. (1), $p$ is the required filtration pressure, $p_{s}$ a constant, $K$ the system gain, $\varepsilon$ the flow error (set point - measured value), $t$ is time, $T_{i}$ the integral time and $\tau_{d}$ the derivative time. The rate and magnitude of the pressure adjustments were dependent on the nature of the feed, the compressibility of the filter cake and the desired process conditions. For the illustrative purposes of this paper, only data obtained with a proportional controller are presented such that $p=p_{s}+K \varepsilon$. In order to monitor the changing properties in a filter cake during a test, series of small electrodes were fitted internally within a filter cell. The electrodes protruded a short distance into the cell and could be arranged either in single vertical planes or, for maximum information, in sequences of horizontal rings. Signals to electrode pairs were switched by the computer via electronic circuitry to facilitate electrical resistance measurements of transient cake thickness and solids concentration.

The use of computer control allowed filtration data to be acquired in a repeatable and reliable manner with a minimum of operator interference for either constant or variable pressure conditions. The on-line measurement of experimental parameters also allowed a real time display of results on the computer screen as an experiment proceeded. A Ziegler-Nichols analysis and some preliminary experimental investigations showed that a proportional algorithm with a system gain in the region $1-1.5 \times 10^{5}$ was suited to the provision of a constant flow when distilled water alone was used [18]. Initial experiments also showed that the open-loop flow response behaviour of the apparatus was similar to a first order system with a time delay. When (closed-loop) negative feedback control was used to provide constant flow filtration the apparatus typically behaved with an underdamped second order response such that an overshoot was followed by an oscillatory decay to a constant flow.

The filtration materials chosen for the investigation spanned a range of cake compressibilities that could be altered (significantly in some cases) by changing the ionic composition of the solution environment. In the general sense, calcite behaved as a material forming low compressibility cakes whereas talc and zinc sulphide would typically form moderately compressible cakes (see Table 1). Prior to an experiment a feed suspension made up from a powder and distilled water was mixed for a suitable period of time to ensure homogeneity and placed within the stirred feed vessel to equilibrate after the $\mathrm{pH}$ had been altered to the desired level. During a (constant flow) test a pressure was set and this was maintained for a given sampling time. The average filtrate flow rate was determined for the sampling period and the filtration pressure required to correct any flow error was calculated via a control algorithm. The required signal was subsequently sent from the computer to the pressure regulator to maintain the calculated pressure throughout the next sampling period whence the procedure was repeated. In this manner 'constant flow' filtrations proceeded until an experiment reached the maximum allowed time or the maximum system pressure of $600 \mathrm{kPa}$; with the latter constant pressure filtration commenced and continued until the end of an experiment.

\section{EXPERIMENTAL RESULTS}

The experimental data in Figures 2-7 illustrate some typical results from the apparatus described. Other examples of similar data have also been obtained and some aspects of accuracy and repeatability for parts of the apparatus have previously been described [11, 18]. In brief, experimental data could be repeated with some confidence provided normal care was taken in preparing the feed suspensions. Variations in flow or pressure response were minimal and typically significantly less than $5 \%$ of a nominal value for supposedly identical tests. 
Figure 2 shows constant pressure filtration data for two different suspension types. The data emphasise the correct sequential nature of experiments when a mechatronics approach is taken and also highlight the increased difficulty of filtering suspensions forming compressible (talc) rather than nearly incompressible (calcite) cakes. The data in Figure 3 illustrate that by the computer switching of diametrically opposed electrode pairs within a filter cell, transient solids concentration profiles could be measured throughout a range of cake formations. Low compressibility cakes form with a near uniform solids concentration throughout the cake thickness giving a relatively sharp transition from suspension to cake. Conversely, cakes which exhibit increased compressibility show a greater range of solids concentrations, and hence specific resistances, throughout the cake thickness and a more obscure transition from suspension to cake. This difficulty makes the determination of transient cake thickness more problematical, although a reasonable value for the transition concentration can be assumed. In some cases, such as with zinc sulphide, relatively slow filtration rates led to longer filtration times. When conditions allowed this provided for some degree of settling within the filter chamber and in the filtering suspension above the cake where particles could potentially rest on the protruding electrodes a transient variability in solids concentration measurements was sometimes observed. Within the cake (which is of greater interest), however, solids concentration readings showed less variability and electrode readings were typically within a few percent of a value determined from a physical sample of cake.

When proportional control was used to provide a constant flow/variable pressure filtration a flow response of the form shown in Figure 4 was typically observed and characterised as shown. The data in Figure 5 illustrate some experimental flow and pressure responses for a constant flow calcite filtration which are typical of underdamped proportional control whereby the overshoot flow response observed toward the start of filtration was followed by the expected decaying oscillatory response. For the example shown the flow settled after $\sim 80 \mathrm{~s}$ (or four sampling intervals) to within $\pm 5 \%$ of an essentially equilibrium flow which was $\sim 19 \%$ below the desired flow ${ }^{\dagger}$. During the constant rate period the filtration pressure increased in a near linear manner in accordance with classical filtration theory for a low compressibility material. In contrast, Figure 6 illustrates typical data for the constant flow filtration of a talc suspension. Although the pressure and flow responses are similar in general form to those obtained for calcite filtrations, the greater compressibility of a talc cake meant that the control of pressure was generally more difficult and filtrate flows were considerably lower than those for otherwise identical filtrations with calcite. In some cases, such as the data shown in Figure 6 and particularly for higher set point flows, control difficulties lead to a relatively slow but progressive increase in flow offset with time which indicates that a proportional controller may not be suitable for more compressible constant flow filtrations. For a typical talc filtration the pressure response exhibited significant curvature as time proceeded which is in accordance with classical filtration theory.

Investigations of different proportional controller settings showed a range of system responses and a summary of the trends observed for a combination of conditions is shown in Table 2. Here, the affects of altering one operational process parameter from a 'standard' value was evaluated whilst maintaining the other experimental conditions constant. It is evident from Table 2 and other similar data for different combinations of 'standard' conditions that proportional control is capable of providing reasonable control in variable pressure filtrations provided the cake compressibility or desired flow rate is not too high. In many constant flow filtration experiments control within $\pm 5 \%$ of an equilibrium flow was achieved after less than five sampling intervals. The general effects of

\footnotetext{
${ }^{\dagger}$ In the context of this paper, response time is defined as the time required for the initial flow oscillations to settle within $\pm 5 \%$ of the constant flow achieved, rather than the time required to achieve a flow within $\pm 5 \%$ of the set point. Although ultimately undesirable, a (reasonable) flow offset is not considered to be a critical problem at the current stage of development. A rapid response to the equilibrium flow is more important as deviations in flow and/or pressure may have undesirable consequences for cake formation and the arrangement of initial and subsequent layers of its constituent particles.
} 
increasing proportional gain were (as expected) to reduce the flow offset at the expense of an increased overshoot, whilst at higher set point flows the apparatus response became progressively less oscillatory. With appropriate controller settings a flow response close to a quarter decay ratio could be observed; such a response is often regarded as an 'optimum' control [19]. Although a more sophisticated control regime is likely to be ultimately required, the best response from the apparatus with a proportional controller was obtained for calcite with a sampling time $=5$ or $10 \mathrm{~s}$, proportional gain $=1 \times 10^{5}$, initial pressure $=100 \mathrm{kPa}$ and a set point flow $=4 \times 10^{-6} \mathrm{~m}^{3} \mathrm{~s}^{-1}$. Corresponding values for talc filtrations were respectively $10 \mathrm{~s}, 3 \times 10^{5}, 100 \mathrm{kPa}$ and $1.5 \times 10^{-6} \mathrm{~m}^{3} \mathrm{~s}^{-1}$.

\section{DISCUSSION}

It is evident from the example data shown in Figures 2-6 and Table 2 that the coupling of a filtration apparatus with mechatronics technology provides a facility for investigating a range of cake filtration processes. The ability to perform constant pressure, constant flow and (potentially) variable pressure/flow tests at the laboratory (and pilot) scale with a single and versatile experimental apparatus opens many new avenues of research. Suspensions are introduced to a filter in a consistent manner and, through appropriate control of the delivery pressure and flow monitoring, filtrations can be performed to mimic industrial pumping operations with both positive displacement and centrifugal pumps. A minimum of shear and turbulence induced changes to suspension characteristics occur and comparisons of filtration performance over different pressure and flow regimes can be made with more confidence, to the undoubted benefit of scale-up, filter sizing and design procedures.

Despite fundamental shortcomings, classical filtration theory and its associated design equations are still widely used within commercial organisations to analyse filtration data and size filters; the latter being achieved through a combination of the data and results obtained from laboratory and maybe pilot scale tests, empiricism and heuristics. Design equations based on classical filtration theory are used for illustrative purposes in Figures 7-9 to further highlight the benefits of the mechatronic approach. Although well known, for completeness the principal design equation for constant pressure filtration may be stated as:

$$
t=\frac{\alpha_{a v} \mu \rho M_{s}}{2 A^{2} \Delta p\left(1-M_{s}\left(1+e_{a v}\left(\rho / \rho_{s}\right)\right)\right)} V^{2}+\frac{\mu R_{m}}{A \Delta p} V
$$

where $t$ is the cake formation (filtration) time, $V$ the cumulative volume of filtrate, $\rho$ the filtrate density, $\rho_{s}$ the solids density, $M_{s}$ the solids mass fraction in the feed, $A$ the filter area, $\mu$ the filtrate dynamic viscosity, $\Delta p$ the filtration pressure and $R_{m}$ the filter medium resistance. For constant flow/variable pressure filtration, the most commonly applied equation for design is:

$$
t=\frac{A^{2}\left(1-M_{s}\left(1+e_{a v}\left(\rho / \rho_{s}\right)\right)\right)}{\alpha_{a v} \mu \rho M_{s} Q^{2}}\left(\Delta p-\mu R_{m} \frac{Q}{A}\right)
$$

where $Q$ is the (constant) filtrate flow rate. The concepts of specific cake resistance $(\alpha)$ and cake voids ratio $(e)$ provide a practical indication of cake form and structure and through equations (2) and (3) relate the ease of separation to process variables. When a degree of compressibility exists in a growing cake the use of $\alpha$ and e becomes more abstract as values vary locally throughout the cake height to an extent dependent on the degree of compressibility. In such cases (i.e. the majority of practical filtrations) our present level of filtration knowledge necessitates the definition of average values such that:

$$
\alpha_{a v}=\alpha_{0}(1-n) \Delta p_{c}^{n}
$$


$e_{a v}=e_{0}-b_{1} \cdot \log \left(\Delta p_{c}\right)$

where $\Delta p_{c}$ is the pressure gradient across the cake (which for design purposes can be approximated to $\Delta p$ ) and $\alpha_{0}, n, e_{0}$ and $b_{1}$ are empirical or scale-up constants usually derived from sequences of constant pressure experiments. The need to know relationships for scale-up constants generally becomes more important as the cake compressibility increases [10]. In Figure 7 the scale-up constants given in Table 2 have been used in combination with equations (2), (4) and (5) to provide predictions of $V$ vs. $t$. The predictions of performance are good in comparison with the experimental data for each of the three different suspensions (which have significantly different properties) and certainly adequate for filter design purposes. The significance of the mechatronics approach becomes more apparent, however, when it is realised that the majority of the scale-up constants used in the calculations were obtained using a different and separate mechatronic based filtration apparatus. The ability to predict the performance of a filter using scale-up data from another provides further evidence of the benefits of applying mechatronic principles to filtration and indicates a basis from which to develop standard test procedures, test equipment and filter design procedures. It is noted in passing that some data showing predictions of cake growth rate have previously been reported by the author [11].

When equation (3) is used to analyse constant flow filtration data, values for $\alpha_{a v}$ and $e_{a v}$ can be calculated. As the filtration pressure changes throughout a test, these average values are supposedly representative of all values between the minimum and maximum pressures observed. Equation (3) can also be used in a predictive sense by combining with equations (4) and (5), whence it is implicitly assumed that the scale-up constants derived from series of constant pressure data (e.g. those values shown in Table 2) can be used to predict filtration performance over a different pressure/flow regime. Indeed, such a procedure is recommended practice in scale-up calculations when it is combined with a 'factor of safety' [20]. Figures 8 and 9 illustrate the predictive use of equations (3)-(5) and Figure 9 in particular shows why a factor of safety is required. The data in Figure 8 for the low compressibility calcite system filtered at different constant flows indicate that reasonable predictions of performance can be made. In Figure 9 with the higher compressibility talc system significant differences between theoretical predictions and experimental data are typically seen. Several researchers [15-17], including the author [18], have questioned the philosophy of combining filtration data obtained over different pressure/flow regimes as there are inherent differences between cakes formed under conditions of constant and variable pressure. When compressibility is present in a forming cake, the rate of change in the pressure gradient across the cake affects the manner in which the particles in the cake are arranged, and this in turn influences both cake resistance and cake porosity. Much of the recent, and indeed past, filtration modelling work has found difficulty in quantifying these differences and several models assume that layers of forming cake instantaneously achieve an equilibrium solids concentration rather than undergo some form of dynamic secondary consolidation and/or require the a priori measurement of experimental data in order to predict performance of the same test [2123]. This is an undesirable situation and one which can hopefully be remedied, at least in part, by providing reliable experimental data against which to compare and develop future theoretical models of filtration.

\section{CONCLUSIONS}

The philosophy and example data presented in this paper have shown the potential benefits of using mechatronics technology in filtration experiments, and at the current stage of development it is perhaps the philosophy of the approach which is more important than the data or theories presented. The work undertaken to date has allowed the production of a single, fully automated, computer controlled, apparatus which facilitates repeatable experiments over a range of pressure/flow regimes that mimic the operation of industrial filtrations using positive displacement and (potentially) centrifugal pumps. In the wider context separations can be performed at laboratory or semi-technical scales through any chosen pressure/flow regime without changing the 
properties of the feed in an inappropriate, and un-quantifiable, manner. Whilst more data are required for significant theoretical advances to be made, the work described here can provide the platform on which to base standard filtration equipment and analysis procedures and may eventually lead to (for instance) the development of intelligent filters where process conditions can be adapted in real time to provide for optimum filtration.

The state-of-the-art apparatus described in this paper perhaps represents the limits of what can be achieved with today's readily available technology. Such an apparatus, however, is yet to be used widely for the acquisition of filtration data and there is likely to be reliance on more basic equipment for some years to come. The greater cost and potential accuracy of complex and sophisticated filtration equipment must of course be justified in relation to the more conventional techniques. However, the ability to perform otherwise very difficult, but more revealing, experiments may ultimately lead to the preferential adoption of such techniques.

\section{ACKNOWLEDGEMENTS}

The author wishes to acknowledge the financial support of the EPSRC and Dupont for funding parts of the research presented in this paper.

\section{NOMENCLATURE}

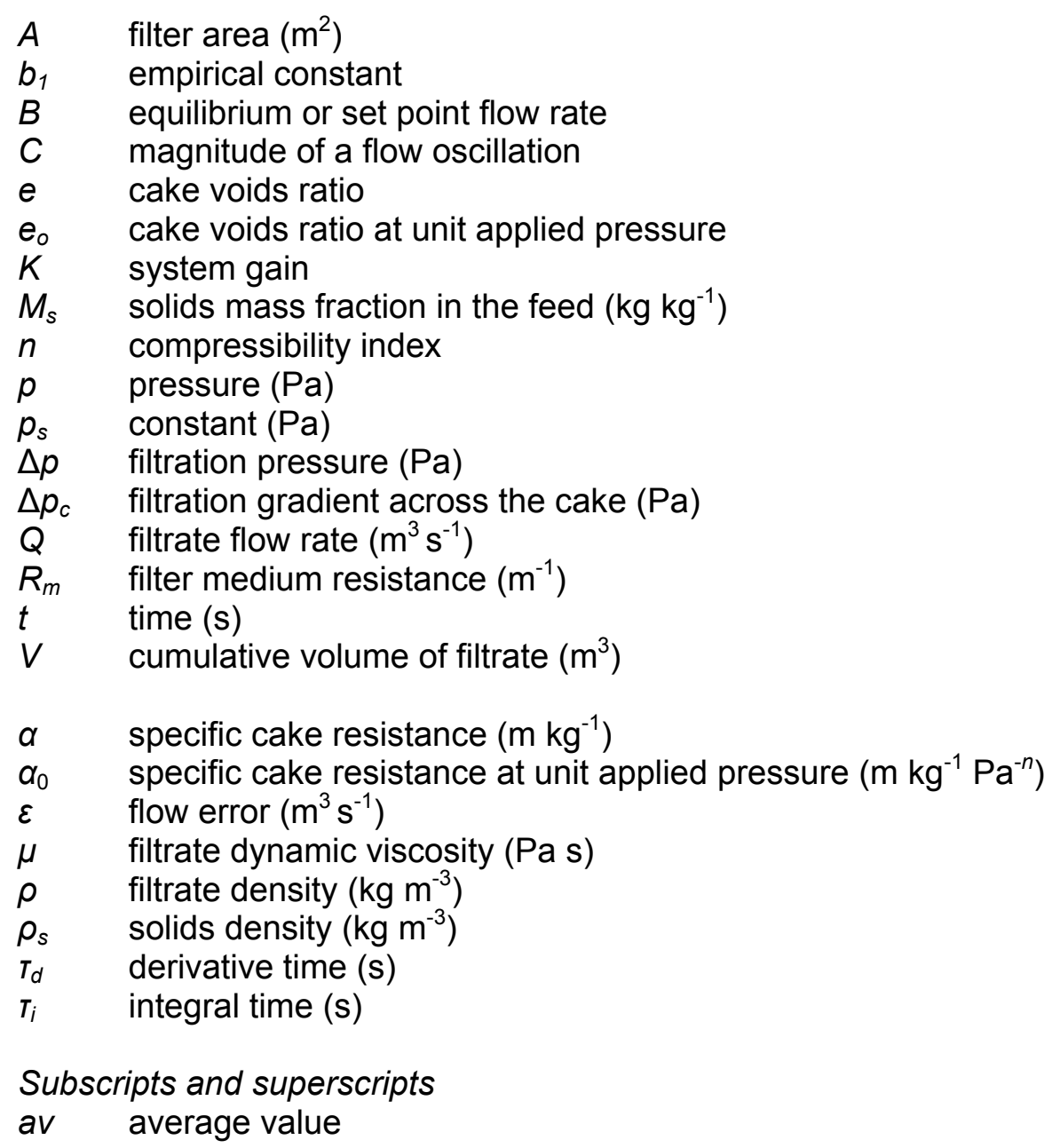

\section{REFERENCES}


1. R.J. Wakeman and E.S. Tarleton, Filtration: Equipment Selection, Modelling and Process Simulation, Elsevier, Oxford, (1998).

2. Rushton, M. Hosseini and I. Hassan, The effects of velocity and concentration on filter cake resistance, J. Separ. Proc. Technol., 1(3) (1980) 35.

3. K. Stamatakis and C. Tien, Cake formation and growth in cake filtration, Chem. Eng. Sci., 46(8) (1991) 1917.

4. Y. Wu, An analysis of constant pressure filtration, Chem. Eng. Sci., 49(6) (1994) 831.

5. R.J. Wakeman, A numerical integration of the differential equations describing the formation of and flow in compressible filter cakes, Trans IChemE, 56(A) (1978) 258.

6. M.S. Willis, R.M. Collins and W.G. Bridges, Complete analysis of non-parabolic filtration behaviour, Chem. Eng. Res. Des., 61 (1983) 96.

7. D.J. Lee, Filter medium clogging during cake filtration, AlChEJ, 43(1) (1997) 273.

8. C. Tien, R. Bai and B.V. Ramarao, Analysis of cake growth in cake filtration: Effect of fine particle retention, AlChEJ, 43(1) (1997) 33.

9. W-M Lu, K-L Tung and K-J Hwang, Effect of woven structure on transient characteristics of cake filtration, Chem. Eng. Sci., 52(11) (1997) 1743.

10. E.S. Tarleton and S.A. Willmer, The effects of scale and process parameters in cake filtration, Trans IChemE, 75(A) (1997) 497.

11. E.S. Tarleton and D.L. Hancock, Using mechatronics for the interpretation and modelling of the pressure filter cycle, Trans IChemE, 75(A) (1997) 298.

12. F.M. Tiller, The role of porosity in filtration Part 3: Variable-pressure variable-rate filtration, AIChEJ, 4(2) (1958) 170.

13. M. Shirato, T. Aragaki, E. Iritani and T. Funahashi, Constant rate and variable pressure variable rate filtration of power-law non-Newtonian fluids, J. Chem. Eng. Japan, 13(6) (1980) 473.

14. M. Shirato, M. Sambuichi, T. Murase, T. Aragaki, K. Kobayashi and E. Iritani, Theoretical and experimental studies in cake filtration, Memoirs Faculty Engineering Nagoya University, 37(1) (1985) 38.

15. S.M. Walas, Resistance to filtration, Trans. Am. Inst. Chem. Engrs., 42 (1946) 783.

16. P.C. Carman, Fundamental principles of industrial filtration, Trans. Am. Inst. Chem. Engrs., 16 (1938) 168.

17. M.L. Arora, Constant-rate and constant-pressure filtration look similar - but are they, AWWAJ, May (1978) 267.

18. E.S. Tarleton, A new approach to variable pressure cake filtration, Min. Engng., 11(1) (1998) 53. 
19. D.R. Coughanowr, Process Systems Analysis and Control (2 $2^{\text {nd }}$ Edn.), pp.282-302, McGraw-Hill, New York, 1991.

20. D.B. Purchas and R.J. Wakeman, Solid/Liquid Separation Equipment Scale-up (2nd Edn.), pp.411-446, Uplands Press, London, 1986.

21. R.J. Wakeman, The formation and properties of apparently incompressible filter cakes under vacuum on downward facing surfaces, Trans IChemE, 59 (1981) 260.

22. W-M Lu and K-J Hwang, Mechanism of cake formation in constant pressure filtrations, Sep. Technol., 3 (1993) 1993.

23. H. Theliander and M. Fathi-Najafi, Simulation of the build-up of the filter cake, Proc. Filtech Conference, pp.127-138, Filtration Society, Karlsruhe, Germany, 1995. 


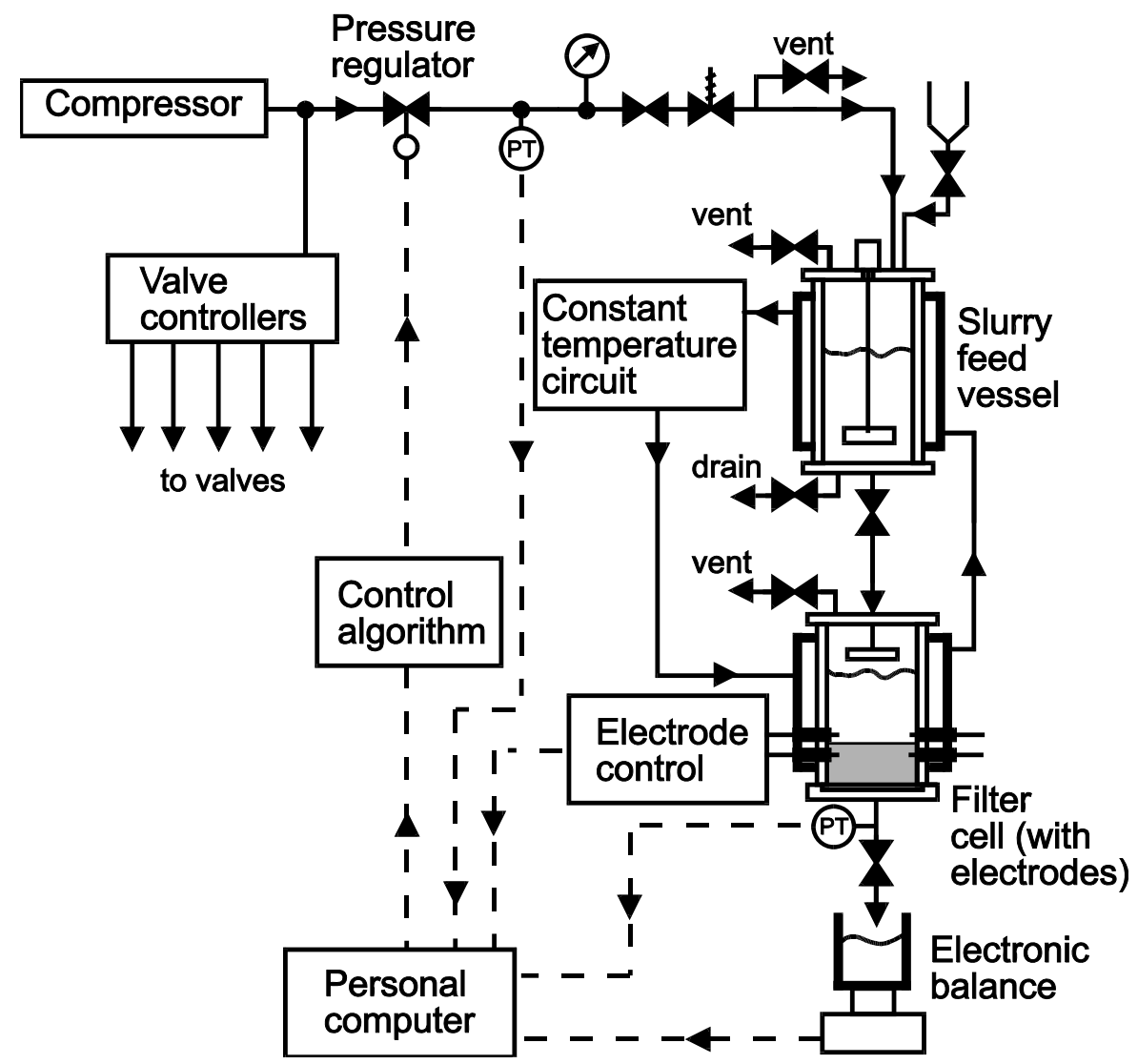

Figure 1: Schematic representation of the mechatronic based filtration apparatus. 


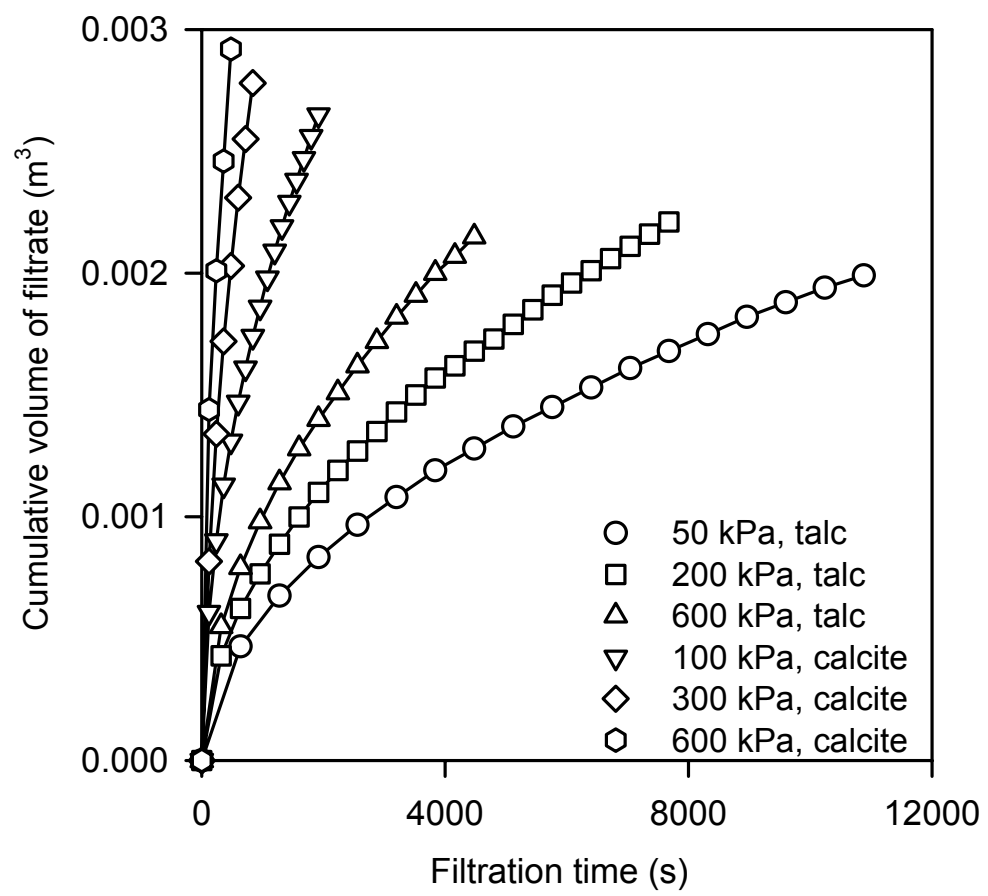

Figure 2: Filtration data sequences for the constant pressure filtration of $10 \% \mathrm{v} / \mathrm{v}$ calcite and talc suspensions.

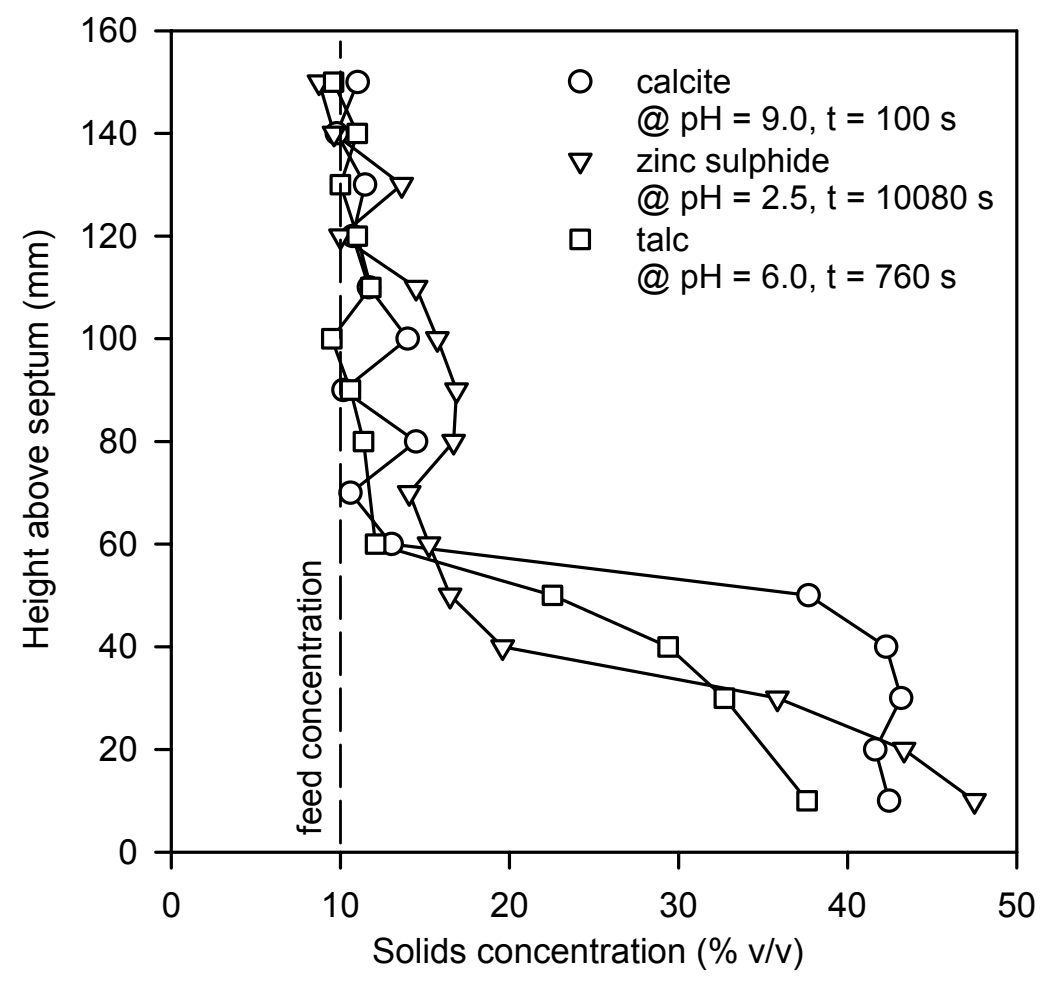

Figure 3: Example transient solids concentration profiles obtained during the constant pressure filtration of suspensions forming cakes with a range of compressibilities. 


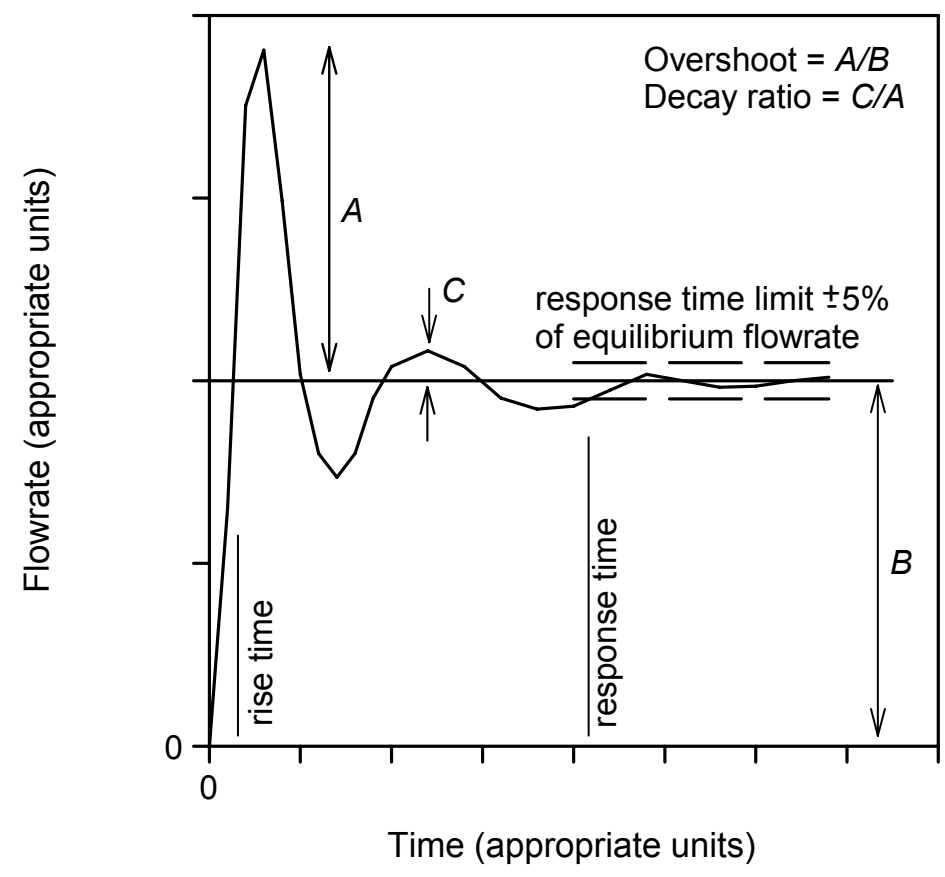

Figure 4: The typical form of the filtration system response with a negative feedback proportional controller showing the characterising parameters.

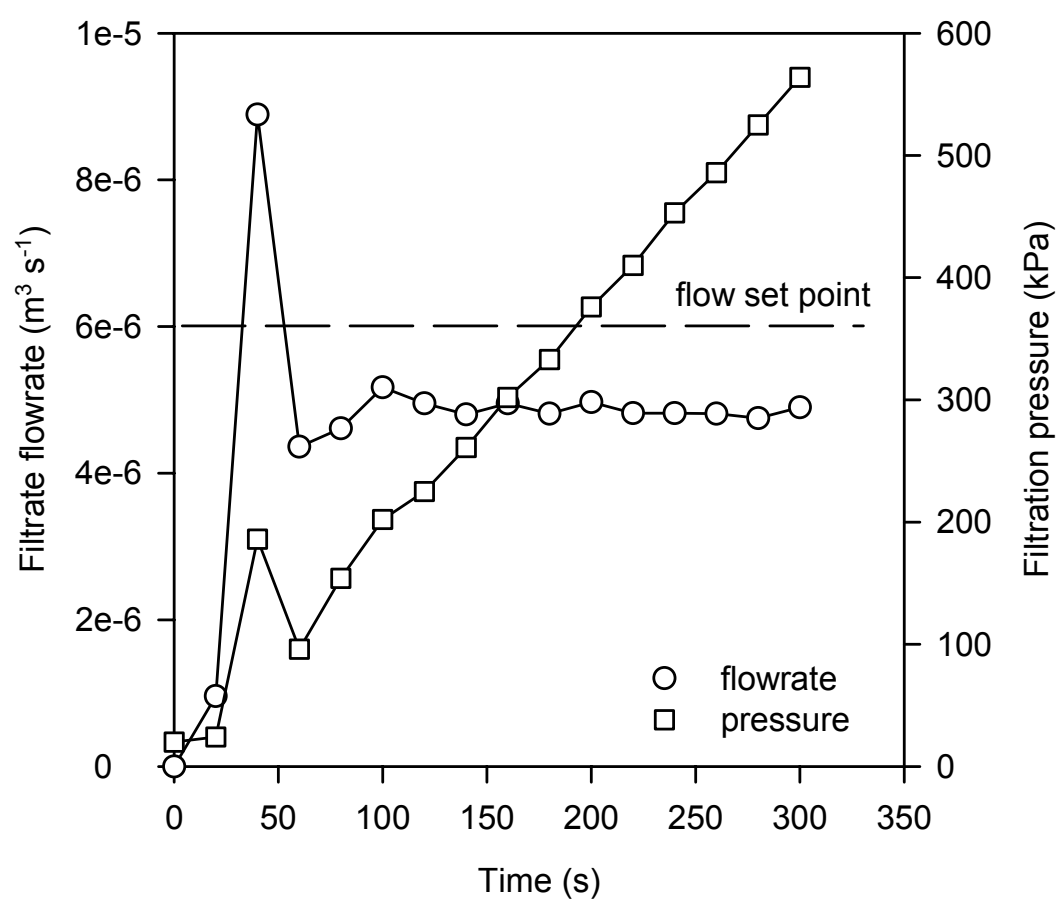

Figure 5: Typical pressure and filtrate flow rate histories for the proportionally controlled, constant flow filtration of a calcite suspension. Experimental conditions: set point $=6 \times 10^{-6} \mathrm{~m}^{3} \mathrm{~s}^{-1}$, proportional gain $=2 \times 10^{5}$, initial pressure $=20 \mathrm{kPa}$ and sampling time $=20 \mathrm{~s}$. 


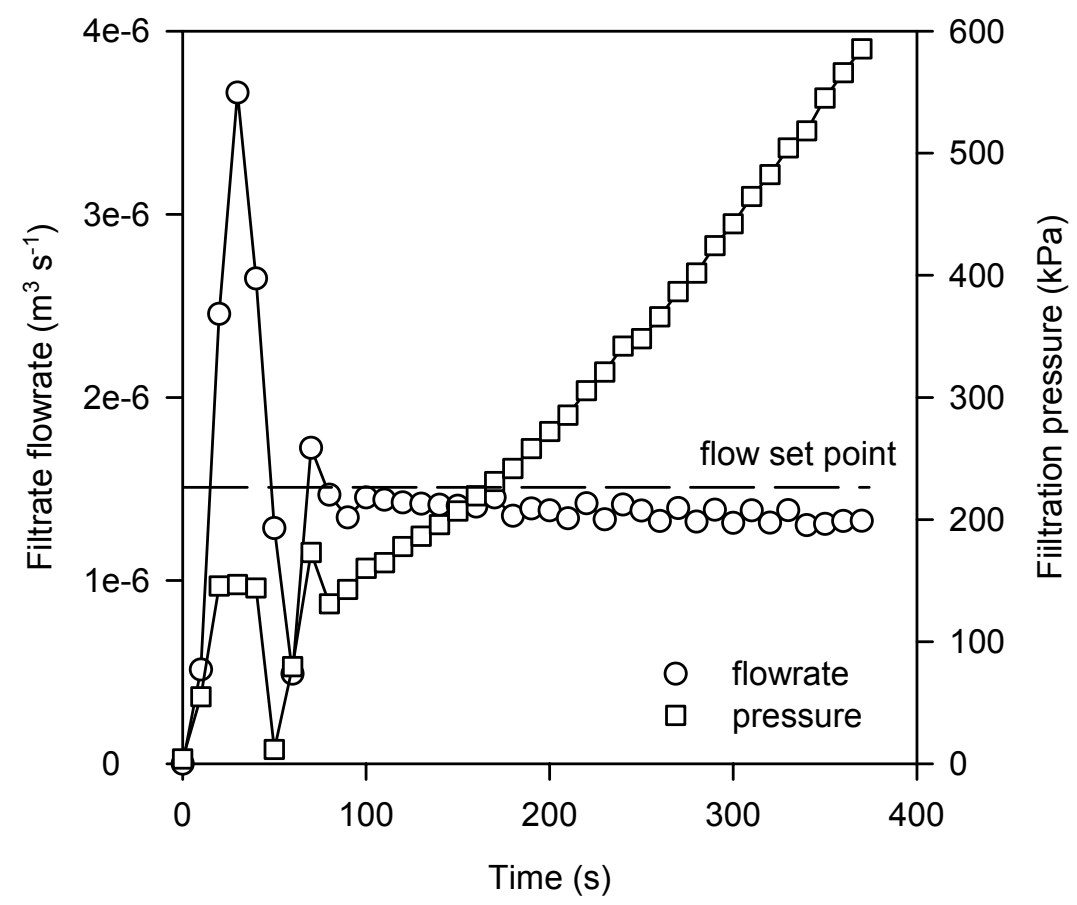

Figure 6: Typical pressure and filtrate flow rate histories for the proportionally controlled, constant flow filtration of a talc suspension. Experimental conditions: set point $=1.5 \times 10^{-6} \mathrm{~m}^{3} \mathrm{~s}^{-1}$, proportional gain $=2 \times 10^{5}$, initial pressure $=20 \mathrm{kPa}$ and sampling time $=10 \mathrm{~s}$.

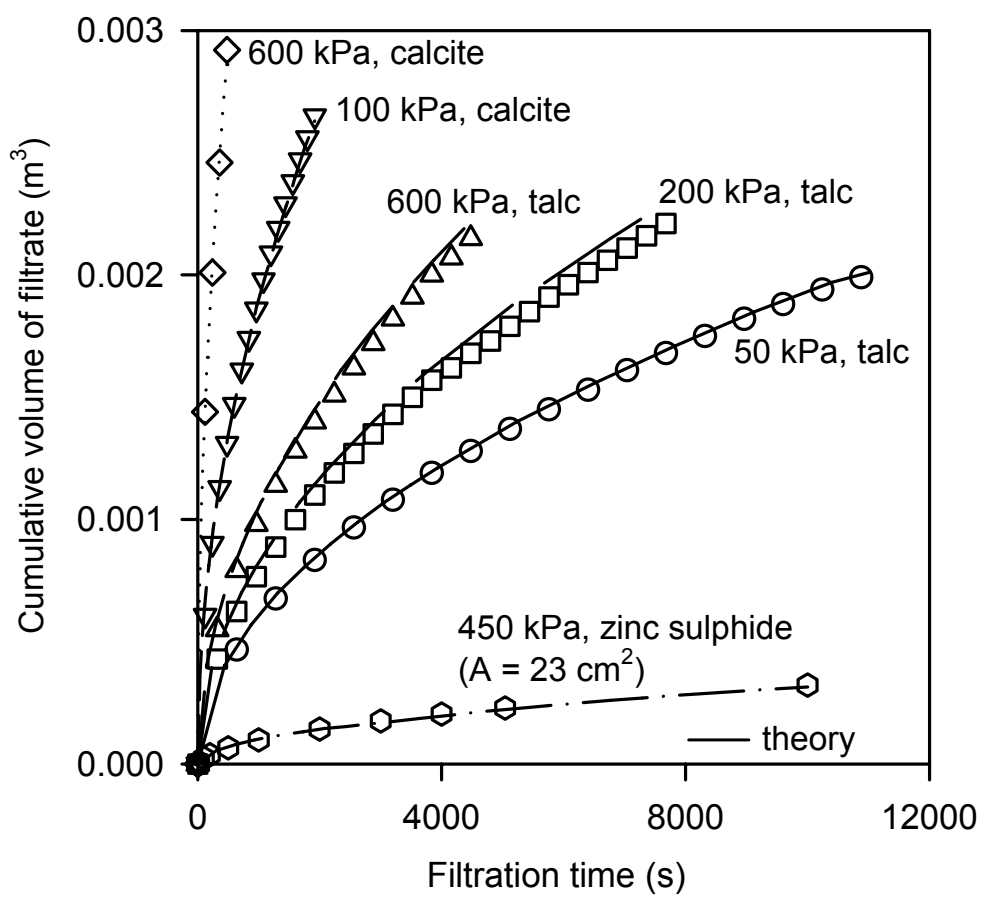

Figure 7: Predictions of constant pressure filtration performance for suspensions forming cakes with a range of properties. 


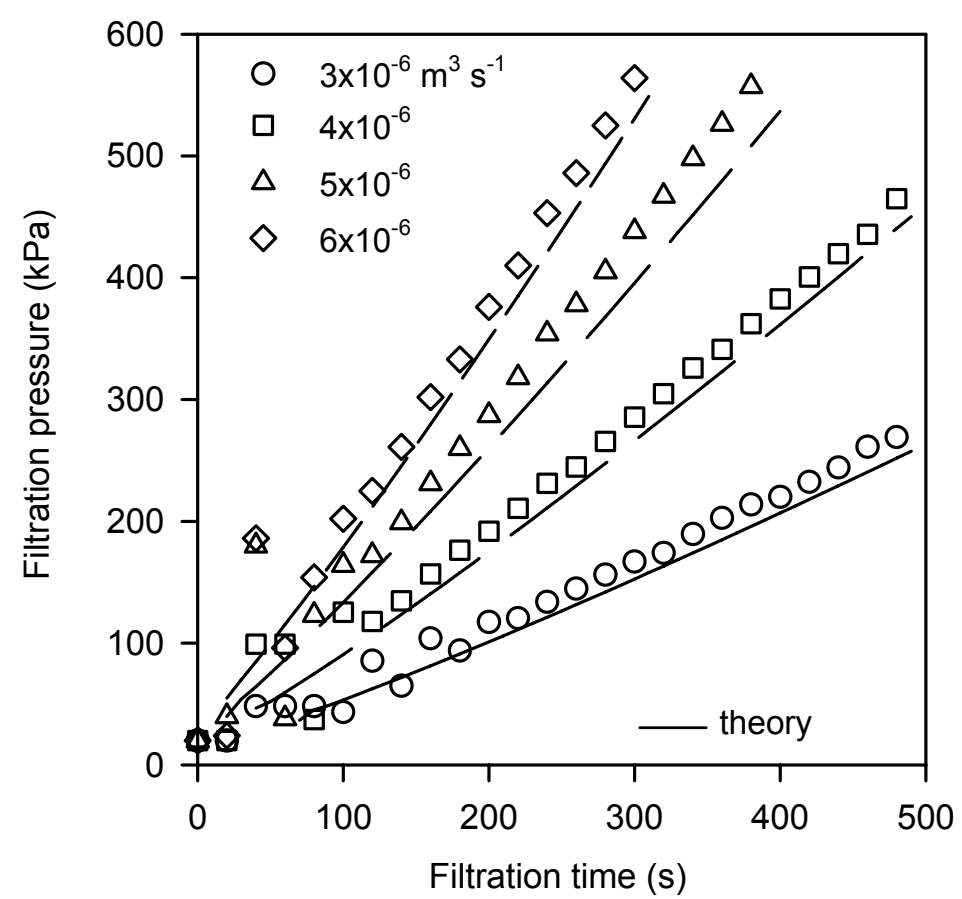

Figure 8: Comparisons between experimental data obtained from the constant flow filtration of calcite suspensions and theoretical predictions made using a combination of constant pressure experimental data and design equations based on classical filtration theory.

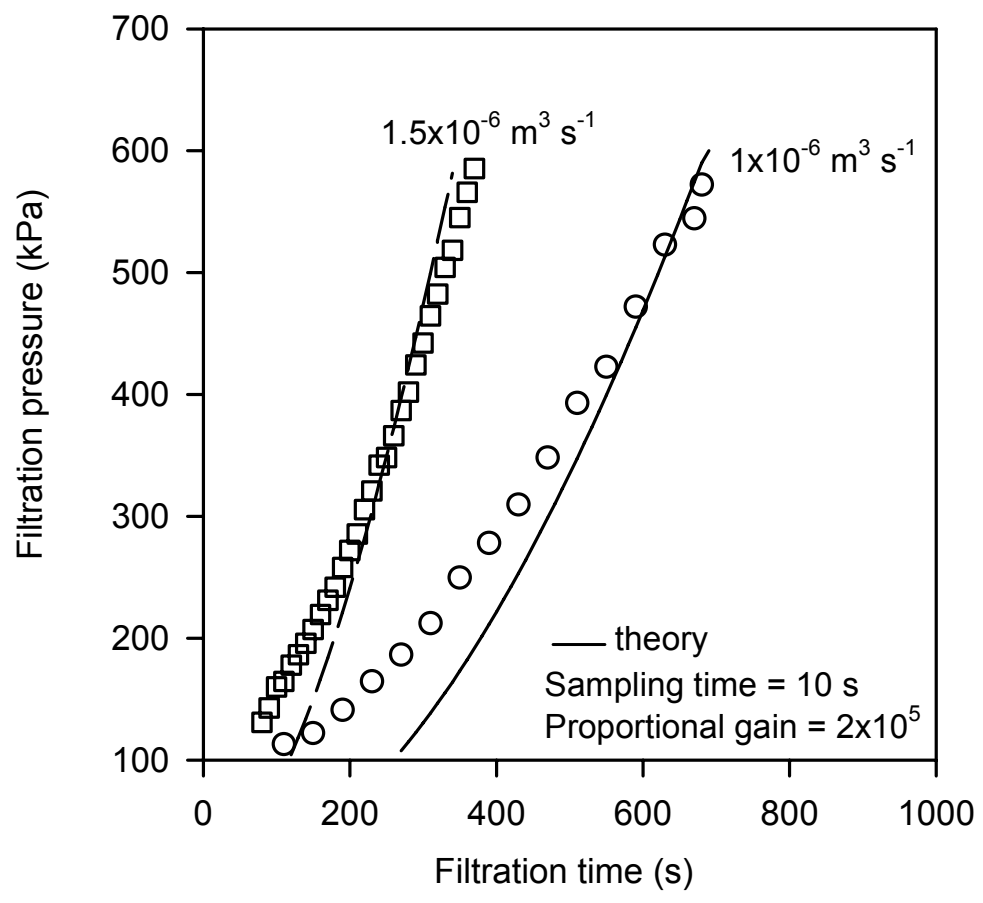

Figure 9: Comparisons between experimental data obtained from the constant flow filtration of talc suspensions and theoretical predictions made using a combination of constant pressure experimental data and design equations based on classical filtration theory. 


\begin{tabular}{|c|c|c|c|c|}
\hline Measured parameter & Calcite & Talc & $\begin{array}{l}\text { Zinc } \\
\text { sulphide * }\end{array}$ & Membrane \\
\hline $\begin{array}{l}50 \% \text { particle size }(\mu \mathrm{m}) \\
50 \% \text { pore size }(\mu \mathrm{m}) \\
\text { Size variance }\left(\mu \mathrm{m}^{2}\right) \\
\\
\text { Particle shape } \\
\text { Iso-electric } \mathrm{pH} \\
\text { Max. } \zeta \text {-potential }(\mathrm{mV}) \\
\text { Permeability }\left(\mathrm{m}^{2}\right) \\
\text { Thickness }(\mu \mathrm{m})\end{array}$ & $\begin{array}{l}11.3 \\
- \\
215 \\
\text { Rhomboidal } \\
9 \\
-20(\mathrm{pH}=9)^{\ddagger} \\
- \\
-\end{array}$ & $\begin{array}{l}8.5 \\
- \\
\text { not available } \\
\text { Platelet } \\
2^{\dagger} \\
-55(\mathrm{pH}=11)^{\ddagger} \\
- \\
-\end{array}$ & $\begin{array}{l}15.6^{* *} \\
- \\
5780^{* *} \\
\text { Oblate ellipsoid } \\
2^{\dagger+} \\
-50(\mathrm{pH}=12)^{\ddagger} \\
- \\
-\end{array}$ & $\begin{array}{l}- \\
0.25 \\
\text { not } \\
\text { available } \\
- \\
- \\
- \\
7.0 \times 10^{-15} \\
185\end{array}$ \\
\hline $\begin{array}{l}\text { Example scale-up } \\
\text { constants } \neq \neq \\
\alpha_{a v}=\alpha_{0}(1-n) \Delta p_{c}^{n} \\
e_{a v}=e_{0}-b_{1} \cdot \log \left(\Delta p_{c}\right)\end{array}$ & $\begin{array}{l}a_{0}=1.17 \times 10^{9} \\
n=0.198 \\
e_{0}=3.415 \\
b_{1}=0.322\end{array}$ & $\begin{array}{l}a_{0}=1.82 \times 10^{8} \\
n=0.587^{\dagger \dagger} \\
e_{0}=3.701 \\
b_{1}=0.354\end{array}$ & $\begin{array}{l}\alpha_{0}=6.14 \times 10^{9} \\
n=0.417^{\dagger \dagger} \\
e_{0}=1.790 \\
b_{1}=0.07\end{array}$ & - \\
\hline
\end{tabular}

Analar grade $\mathrm{HCl}^{\dagger}, \mathrm{CH}_{3} \mathrm{COOH}^{\dagger \dagger}$ or $\mathrm{NaOH}^{\ddagger}$ used to alter $\mathrm{pH}$.

$\ddagger \ddagger$ Obtained from series of constant pressure experiments (pressure in $\mathrm{Pa}$ ). Values shown are examples, magnitudes were $\mathrm{pH}$ and solution environment dependent.

${ }_{* *}^{*}$ Dispex (an Allied Colloids surfactant) was added to these suspensions.

${ }^{* *}$ measured $50 \%$ size was highly $\mathrm{pH}$ dependent and varied between 3.5 and $18 \mu \mathrm{m}$ over the $\mathrm{pH}$ range $2-12$.

Table 1: Characterisation data for the feed suspensions and Versapor membrane. 


\begin{tabular}{|c|c|c|c|c|}
\hline \multirow{2}{*}{$\begin{array}{l}\text { Control } \\
\text { response } \\
\text { parameter }\end{array}$} & \multicolumn{4}{|c|}{ Controller settings } \\
\hline & Sampling time & $\begin{array}{l}\text { Proportional } \\
\text { gain }\end{array}$ & Initial pressure & Set point flow \\
\hline \multicolumn{5}{|l|}{ Calcite } \\
\hline $\begin{array}{l}\text { (Range } \\
\text { investigated) }\end{array}$ & $5-40 \mathrm{~s}$ & $0.5-6 \times 10^{5}$ & $0-200 \mathrm{kPa}$ & $2-6 \times 10^{-6} \mathrm{~m}^{3} \mathrm{~s}^{-1}$ \\
\hline Overshoot & $\begin{array}{l}\text { decreases } 4.2 \rightarrow \\
0.9 \text { up to } 20 \mathrm{~s} \text { then } \\
\text { constant }\end{array}$ & $\begin{array}{l}\text { linear increase } \\
0.6 \rightarrow 3.2\end{array}$ & $\begin{array}{l}\text { minimum of } 0.9 @ \\
\sim 35 \mathrm{kPa}\end{array}$ & $\begin{array}{l}\text { maximum of } 0.8 \\
@ 4 \times 10^{-6} \mathrm{~m}^{3} \mathrm{~s}^{-1}\end{array}$ \\
\hline Offset & $\begin{array}{l}\text { linear increase } 1.8 \\
\rightarrow 9.6 \%\end{array}$ & $\begin{array}{l}\text { decrease } 16.8 \\
\rightarrow 0.9 \%\end{array}$ & negligible effect & $\begin{array}{l}\text { linear increase } \\
2.1 \rightarrow 18.6 \% \\
\end{array}$ \\
\hline Rise time & $\begin{array}{l}\text { linear increase } 8 \rightarrow \\
55 \mathrm{~s}\end{array}$ & $\begin{array}{l}\text { linear decrease } \\
30 \rightarrow 22 \mathrm{~s}\end{array}$ & decrease $25 \rightarrow 5 \mathrm{~s}$ & $\begin{array}{l}\text { little effect, } \\
\text { typically } 30 \mathrm{~s}\end{array}$ \\
\hline $\begin{array}{l}\text { Response } \\
\text { time }\end{array}$ & $\begin{array}{l}\text { near linear } \\
\text { increase } 150 \rightarrow \\
300 \mathrm{~s} \\
\end{array}$ & $\begin{array}{l}\text { increase } 80 \rightarrow \\
240 \mathrm{~s}\end{array}$ & $\begin{array}{l}\text { decrease } 190 \rightarrow \\
120 \mathrm{~s}\end{array}$ & $\begin{array}{l}\text { decrease } 250 \rightarrow \\
80 \mathrm{~s}\end{array}$ \\
\hline \multicolumn{5}{|l|}{$\underline{\text { Talc }}$} \\
\hline $\begin{array}{l}\text { (Range } \\
\text { investigated) }\end{array}$ & $5-40 s$ & $0.5-4 \times 10^{5}$ & $20-300 \mathrm{kPa}$ & $0.5-2 \times 10^{-6} \mathrm{~m}^{3} \mathrm{~s}^{-1}$ \\
\hline Overshoot & decrease $3 \rightarrow 0.6$ & $\begin{array}{l}\text { near linear } \\
\text { increase } 0.2 \rightarrow \\
2.6\end{array}$ & increase $0.8 \rightarrow 4.2$ & decrease $7 \rightarrow 1$ \\
\hline Offset & increase $5 \rightarrow 20 \%$ & $\begin{array}{l}\text { near linear } \\
\text { decrease } 20 \rightarrow \\
4 \%^{\dagger} \\
\end{array}$ & negligible effect & $\begin{array}{l}\text { linear increase } 1 \\
\rightarrow 10 \%\end{array}$ \\
\hline Rise time & increase $6 \rightarrow 100 \mathrm{~s}$ & $\begin{array}{l}\text { linear decrease } \\
20 \rightarrow 12 \mathrm{~s}\end{array}$ & decrease $15 \rightarrow 2 \mathrm{~s}$ & $\begin{array}{l}\text { near linear } \\
\text { decrease } 15 \rightarrow \\
10 \% \\
\end{array}$ \\
\hline $\begin{array}{l}\text { Response } \\
\text { time }\end{array}$ & $\begin{array}{l}\text { linear increase } 100 \\
\rightarrow 160 \mathrm{~s}\end{array}$ & $\begin{array}{l}\text { linear increase } \\
40 \rightarrow 120 \mathrm{~s}\end{array}$ & $\begin{array}{l}\text { linear decrease } \\
110 \rightarrow 60 \mathrm{~s}\end{array}$ & $\begin{array}{l}\text { decrease } 270 \rightarrow \\
70 \mathrm{~s}\end{array}$ \\
\hline
\end{tabular}

† Some individual experiments showed a slow but progressive increase in flow offset with time (see also Figure 6).

Table 2: Summary of the affects of changing proportional controller settings on system response for calcite and talc constant flow filtrations. Standard experimental conditions for calcite: sampling time $=20 \mathrm{~s}$, proportional gain $=2 \times 10^{5}$, initial filtration pressure $=20 \mathrm{kPa}$ and set point flow $=3 \times 10^{-6}$ $\mathrm{m}^{3} \mathrm{~s}^{-1}$. For talc, corresponding values are $10 \mathrm{~s}, 2 \times 10^{5}, 20 \mathrm{kPa}$ and $1.5 \times 10^{-6} \mathrm{~m}^{3} \mathrm{~s}^{-1}$. 